\title{
An investigative case study at local hospital into the current reliability of blood pressure sphygmomanometers
}

\author{
Vinícius Naves Rezende Faria ${ }^{*}$, Gustavo Mendonça ${ }^{2}$, Daniel Baldoíno de Souza ${ }^{2}$, \\ Adriano Alves Pereira ${ }^{2}$, Rosenda Valdés Arencibia ${ }^{1}$, Selma Terezinha Milagre ${ }^{2}$ \\ ${ }^{1}$ Postgraduate Program in Mechanical Engineering, Federal University of Uberlândia, Uberlândia, MG, Brazil. \\ ${ }^{2}$ Postgraduate Program in Biomedical Engineering, Federal University of Uberlândia, Uberlândia, MG, Brazil.
}

\begin{abstract}
Introduction: Arterial Blood Pressure is a significant indicator of the current health condition of an individual. The correct detection of hypertension is essential, where this health problem is considered as one of the greatest health risks factors that affect the heart and circulatory system. This paper presents the importance of the application of metrological criteria for the diagnosis of hypertension using a sphygmomanometer aneroid. Methods: 72 mechanical aneroid sphygmomanometers were calibrated using a standard manometer and the indication error, hysteresis, air leakage and rapid exhaust were determined; readings of these sphygmomanometers were compared to a properly calibrated and adjusted aneroid sphygmomanometer to carry out pressure measurements as those made during the hypertension diagnosis; the uncertainty of measurement associated with the sphygmomanometers calibration, and pressure values was assessed according to the recommendations of the Guide to the Expression of Uncertainty in Measurement, defined by the Joint Committee for Guides in Metrology. Results: The results obtained have shown that about $61 \%$ of the evaluated aneroid sphygmomanometers did not meet the specifications. The variable that most contributed to the final calibration uncertainty was the hysteresis of the standard manometer, with 53\% of contribution, followed by the sphygmomanometer resolution with $27 \%$. Conclusion: The periodic verifications are essential to evaluate the performance of these devices. It was shown that uncertainty of measurement influences the final diagnosis of hypertension and the application of metrological criteria can increase the reliability of the final diagnosis.
\end{abstract}

Keywords Aneroid sphygmomanometers, Calibration, Uncertainty.

\section{Introduction}

The most commonly measured physiological parameter in the area of medical diagnostics is Arterial Blood Pressure (ABP). It is an important vital sign as to the indication of the current state of health of the patient (Pater, 2005). Through the obtainment of ABP measurement results decisions related to diagnosis, prognosis and therapy are adopted (James et al., 2014; Mendonça, 2012; Mendonça et al., 2012). Hypertension is considered one of the greatest health risks factors that

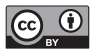

This is an Open Access article distributed under the terms of the Creative Commons Attribution License, which permits unrestricted use, distribution, and reproduction in any medium, provided the original work is properly cited.

How to cite this article: Faria VNR, Mendonça G, Souza DB, Pereira AA, Arencibia RV, Milagre ST. An investigative case study at local hospital into the current reliability of blood pressure sphygmomanometers. Res Biomed Eng. 2017; 33(1):21-30. DOI: 10.1590/2446-4740.02116

*Corresponding author: Postgraduate Program in Mechanical Engineering, Universidade Federal de Uberlândia - UFU, Avenida João Naves de Ávila, 2121, CEP 38408-100, Uberlândia, MG, Brazil. E-mail: naves.vinicius@gmail.com

Received: 05 April 2016 / Accepted: 06 February 2017 affects the heart and the circulatory system (Piper et al., 2015; Yang et al., 2012). For this reason, its correct and early detection is essential to the well-being of any patient. In clinical practice, the diagnosis of hypertension is a common process carried out by the indirect measurement of ABP, this is usually performed through the use of a mechanical aneroid sphygmomanometer and the auscultatory method developed by Korotkoff(Introcaso, 1996; Minor et al., 2012; Powers et al., 2011).

There are a number of factors that can lead to errors in blood pressure (BP) results, such as the patient, operator, equipment and environment. Within such factors one finds: adequate rest time; diurnal variation; room temperature; clinic atmosphere; pain; anxiety; smoking; humidity; end-digit preference; impaired hearing; instrument accuracy; background noise; clothing interference; inappropriate cuff size and placement; posture; inflation-deflation rate; among others These potential error factors place a significant impact on BP readings and are common to clinical practice, highlighting the possibility of inadequate results that lead to misclassification, misdiagnosis, and inadequate 
medical decisions (Pickering and Ogedegbe, 2010; Pickering et al., 2005; Tolonen et al., 2015). Therefore, to obtain valid results from $\mathrm{ABP}$ measurements for hypertension diagnosis, aneroid sphygmomanometer must be accurate, precise and traceable. Traceability includes calibration of equipment as well as the evaluation and declaration of the uncertainty of measurement at every level of the traceability chain, including for the measurement results (International..., 2005). According to JCGM 100 (Joint..., 2008), any measurement result must be given some quantitative indication as to the quality of the result that indicates its reliability, for performing the evaluation and expressing its level of uncertainty. The aneroid sphygmomanometers also should be in line with Ordinance No. 153 (Brasil, 2005) and the Specific Standard No. NIE-DIMEL-006 (Instituto..., 2014), both documents are in accordance with the recommendation of the International Organization of Legal Metrology (OIML) (International Organization..., 2002).

Hence, the objective of this work is to apply a calibration procedure that identifies if the aneroid sphygmomanometers used presently at the Health Care Facility (HCF) meet the stipulated maximums errors of indication and hysteresis. The uncertainty associated with sphygmomanometer calibration and with the measurement results carried out during the hypertension diagnosis are evaluated, and a discussion regarding the effects of uncertainty of measurement on the test diagnosis is presented.

\section{Methods}

The calibration of the aneroid sphygmomanometers was performed at the Laboratory of Bioengineering, located at the Clinical Hospital of the Federal University of Uberlandia (HCU-UFU), according to the Ordinances INMETRO No. 153 (Brasil, 2005) and INMETRO No. DIMEL NIE-006 (Instituto..., 2014). The first ordinance establishes the minimal conditions that the mechanical aneroid sphygmomanometers of noninvasive measurement of human ABP should satisfy (Brasil, 2005). The second establishes which procedures should be adopted in order to evaluate the performance of the mechanical sphygmomanometers (Instituto..., 2014).

The Ordinance No 153 (Brasil, 2005) defines three verifications that should be conducted on the aneroid sphygmomanometers:

- Initial: This should be carried out on all mechanical sphygmomanometers before being marketed;

- Periodic: This should be performed annually and it includes the following tests: Administrative Examination; determination of indication error; and determination of air leakage;
- Eventual: This should be performed after repair or maintenance or upon request by the user. It includes the following tests: administrative examination, determination of the indication error, air leakage, tamper proofing and hysteresis.

The verification procedure denominated as Eventual is one of the items from the maintenance routine for the aneroid sphygmomanometers performed at the hospital considered in this work. At this establishment, the healthcare professional sends the device, judged as non-compliant, to the equipment center of the hospital, which generates the maintenance request using the software "Equipment Management Software". The request is delivered to the Laboratory of Bioengineering, where the responsible technician will carry out the maintenance.

\section{Experiments}

The experiments were divided into two steps. The objective of the first test was to conduct the calibration of the sphygmomanometers, which was divided into The Administrative Examination, which consists of the determination of the Indication Error, Hysteresis, Air Leakage and Rapid Exhaust. The second step was conducted in order to measure Blood Pressure.

\section{Administrative examination}

The Administrative Examination had the purpose of detecting irregularities or damage such as smashed pointer, broken, loosened, and other problems that affect the performance of the device. In this test by means of visual inspection, the detection of noncompliance in the components of the sphygmomanometers was performed. Verified in this examination were Inscriptions and Tamper Proofing.

Inscriptions were evaluated according to the requirement established in regulation $\mathrm{N}^{\circ} .153$ (Brasil, 2005) and the following aspects were observed, presence of measuring unit, trademark that the device is marketed under and scale. It was also evaluated if those inscriptions were clear and easily recognized, without tracing errors, a single color contrasting with the indicator and the device background and if the manometer had approval from Instituto Nacional de Metrologia, Qualidade e Tecnologia (INMETRO).

In Tamper Proofing, verification of the sphygmomanometers measurement mechanism was made. It was also analyzed in respect to protection, closing, dust exposure and tamper violation.

\section{Determination of the indication error and hysteresis}

The pressure readings of devices under calibration were compared to the values indicated by a standard manometer Cappo P-2 which resolution of $0.5 \mathrm{mmHg}$. 
This instrument has a calibration certificate issued by the lab ABSI with the number $127297 / 15$, on 31 August 2015 .

The experiments were carried out in a range from $0 \mathrm{mmHg}$ to $300 \mathrm{mmHg}$ in an incremental manner followed by a decremental manner. Three measurement cycles were performed. The points evaluated during calibration were 0, 30, 70, 90, 100, 120, 150, 190, 230, 270 and $300 \mathrm{mmHg}$. A standard waiting period of one minute was observed in each position before the data registration, in order to guarantee the thermodynamic stabilization of the pneumatic system. Additionally, verification was made to see if the pointer of each aneroid sphygmomanometer was on zero.

From the collected data, the indication error and the hysteresis were calculated for each evaluated point of the nominal range of each aneroid sphygmomanometer. The repeatability and the accuracy were also accessed. Finally, a calibration curve was traced for each equipment. The values of indication error and hysteresis were compared with the maximum permissible error permissible in the Ordinance No. 153 (Brasil, 2005), those being $\pm 3.0 \mathrm{mmHg}$ and $4 \mathrm{mmHg}$ for the indication error and hysteresis, respectively.

\section{Determination of air leakage}

This test identifies leakage from the manometer and cuff. To perform this test, the maximum pressure of the scale range $(300 \mathrm{mmHg})$ was applied over a period of five minutes. If the pressure loss exceeded the $20 \mathrm{mmHg}$ mark after this period, this particular manometer device was reproved in accordance with INMETRO No. DIMEL NIE-006 (Instituto..., 2014).

\section{Determination of rapid exhaust}

In this test, the aneroid sphygmomanometer was pressurized to the maximum pressure of the nominal range and then the deflation valve is fully opened until the pressure decreases to $15 \mathrm{mmHg}$. Devices that spend more than $10 \mathrm{~s}$ to perform this reduction were reproved as recommend by INMETRO No DIMEL NIE-006 (Instituto..., 2014).

\section{Pneumatic system and technologies employed}

The system assembled by the Laboratory of Bioengineering used to perform the calibration is shown in Figure 1. The system uses the pneumatic systems model recommended by NIE-DIMEL-006 (Instituto..., 2014).

The experiments were carried out at $24.0^{\circ} \mathrm{C}$ and $40 \%$ of humidity in accordance to Ordinance No. 153 (Brasil, 2005). Temperature, humidity and time necessary for thermodynamic stabilization of the pneumatic system were monitored during calibration by using a digital thermo-hygrometer clock manufactured by Instrutherm, model HT-210. This equipment has a resolution of $0.1{ }^{\circ} \mathrm{C}$ and a nominal range of $50.0^{\circ} \mathrm{C}$ for temperature, while the

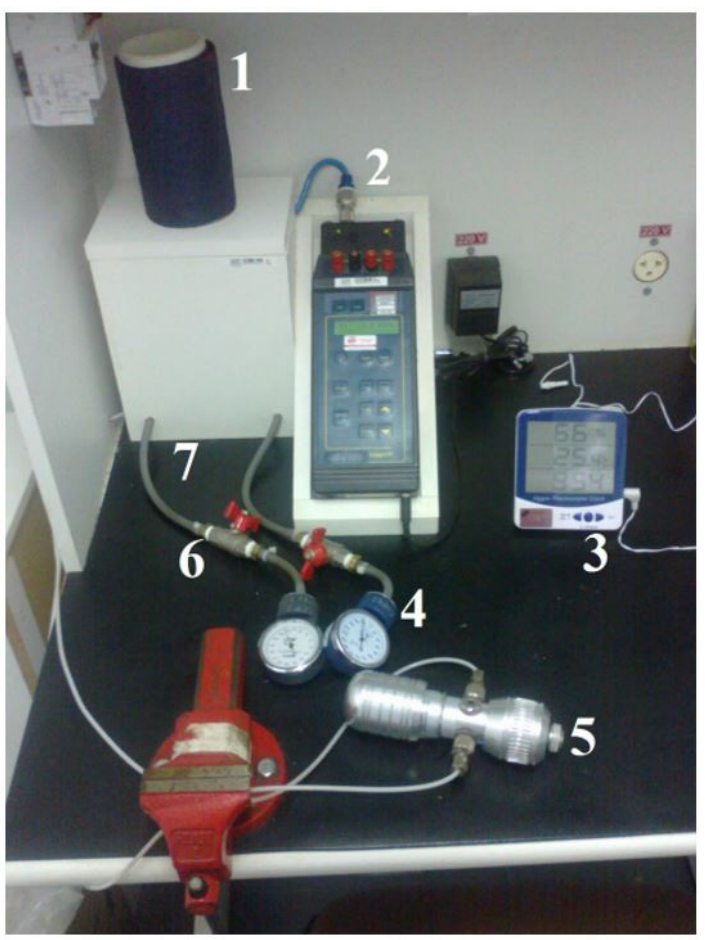

Figure 1. Model assembled by Bioengineering Department for tests. 1- Metal vessel; 2- Standard manometer; 3- Thermo-hygrometer clock; 4- Manometers to be tested; 5- Pressure generator; 6- Register; 7- Connecting hoses.

resolution for humidity is equal to $1 \%$ and nominal range from $20 \%$ to $99 \%$. The expanded uncertainty associated with the thermo-hygrometer clock calibration being equal to $0.2{ }^{\circ} \mathrm{C}$, humidity at $1 \%$ and time at 1 second. In all cases the coverage factor is equal to 2.00 with infinite degrees of freedom.

\section{Blood pressure measure}

An experienced operator measured the systolic (SBP) and diastolic (DBP) blood pressure three times on a single volunteer, these measurements indicated whether the volunteer has normal blood pressure, in according with the Sociedade Brasileira de Cardiologia (Moreira, 2010). This volunteer was used for all experiments. The device used for these initial measurements was a mechanical analog aneroid sphygmomanometer (calibrated and adjusted by the department of clinical engineering of the Federal University of Uberlandia, accredited by INMETRO since 2005 to carry out such procedures) with resolution of $1 \mathrm{mmHg}$ and nominal range of $300 \mathrm{mmHg}$. This equipment has an expanded uncertainty associated with its calibration, which is equal to $1.39 \%$ of the pressure value indicated for $k$ equal to 2.09 and $95.45 \%$ of coverage probability. The hysteresis error is $0.67 \%$ for a pressure around $100 \mathrm{mmHg}$ and $0.33 \%$ for a pressure around $70 \mathrm{mmHg}$. 
The previous readings will serve as a reference of comparison for the other 72 sphygmomanometers used in the hospital and were chosen randomly between departments. In order to check the normality of data resulting from the pressure measurement, 35 measurements were also carried out in the volunteer and values of systolic blood pressure (SBP) and diastolic (DBP) were registered. The Chauvenet criterion was applied to identify extreme values. The Shapiro-Wilk test statistic using the $\mathrm{R}$ software was performed in order to test for normality.

\section{The uncertainty calculation measure}

The uncertainty of measurement was evaluated by applying the method Guide to the Expression of Uncertainty in Measurement (GUM), proposed by the Joint Committee for Guides in Metrology (JCGM) (Joint..., 2008). The mathematical model used to calculate the uncertainty of mechanical aneroid sphygmomanometer calibration, at each point $(j)$ evaluated, is shown in Equation 1. In Equation 2, the mathematical model proposed to estimate the uncertainty of arterial blood pressure measurements is demonstrated.

$P_{j}=\bar{x}_{E j}+\Delta R_{E}+\Delta C_{M j}+\mathrm{H}_{\mathrm{Mj}}$

Reading through Equation $1, P j$ is the pressure at point $j$ of the mechanical aneroid sphygmomanometer nominal range; $\bar{x}_{E j}$ is the average for the values indicated by the calibrated sphygmomanometer for each conventional value indicated by the standard manometer; $\Delta R_{E}$ is the correction due to the resolution of the calibrated sphygmomanometer; $\Delta C_{M j}$ is the correction associated with the calibration uncertainty of the standard manometer at the point $j$; and $H_{M j}$ is the hysteresis of the standard manometer at point $j$.

$$
P=\bar{x}_{P}+\Delta R_{E}+\Delta C_{E}+\mathrm{H}_{\mathrm{E}}
$$

Reading through Equation 2, $P$ is the pressure; $\bar{x}_{P}$ is the average for the values indicated by the sphygmomanometer during pressure measurement; $\Delta R_{E}$ is the correction due to the resolution of the sphygmomanometer; $\Delta C_{E}$ is the correction associated with the uncertainty of the sphygmomanometer; and $H_{E}$ is the hysteresis of the sphygmomanometer.

The combined standard uncertainty associated with the measurements was determined by the application of the law of propagation of uncertainty in Equations 1-2 and, as such, Equations 3-4 were obtained.

$$
\begin{aligned}
& u_{c}^{2}\left(P_{j}\right)=\left(\frac{\partial P j}{\partial \bar{x}_{E j}}\right)^{2} \cdot\left(u_{\bar{x}_{E j}}\right)^{2}+\left(\frac{\partial P j}{\partial \Delta R_{E}}\right)^{2} \cdot\left(u_{\Delta R_{E}}\right)^{2}+ \\
& \left(\frac{\partial P j}{\partial \Delta C_{M j}}\right)^{2} \cdot\left(u_{\Delta C_{M j}}\right)^{2}\left(\frac{\partial P j}{\partial \Delta H_{M j}}\right)^{2} \cdot\left(u_{\Delta H_{M j}}\right)^{2}
\end{aligned}
$$

$$
\begin{aligned}
& u_{c}^{2}(P)=\left(\frac{\partial P}{\partial \bar{x}_{P}}\right)^{2} \cdot\left(u_{\bar{x}_{P}}\right)^{2}+\left(\frac{\partial P}{\partial \Delta R_{E}}\right)^{2} \cdot\left(u_{\Delta R_{E}}\right)^{2}+ \\
& \left(\frac{\partial P}{\partial \Delta C_{E}}\right)^{2} \cdot\left(u_{\Delta C_{E}}\right)^{2}\left(\frac{\partial P}{\partial \Delta H_{E}}\right)^{2} \cdot\left(u_{\Delta H_{E}}\right)^{2}
\end{aligned}
$$

The calculation and declaration of uncertainty associated with the measurement results are particularly useful when the values given by the measuring system are compared with a specification to issue a diagnosis. In this case, the values obtained during the pressure measurement should be compared with those recommended by the World Health Organization (1999) through the International Society of Hypertension (ISH). The expanded uncertainty associated with the measurement results reduces the specification zone, which generates the conformance zone (Weckenmann et al., 2001).

\section{Sampling}

The Annex A of the Specific Standard No. NIE-DIMEL-006 (Instituto..., 2014) establishes the sampling procedure for performing the Initial Verification of the mechanical sphygmomanometers. In accordance with this standard, the sample size must be 50 or more. Thus, 72 sphygmomanometers were randomly collected from among 23 departments of the hospital.

The collected devices were from 9 different trademarks, identified as "A" up to "I", the respective number of collected devices from each trademark was: $\mathrm{A}(1), \mathrm{B}(6)$, $\mathrm{C}(6), \mathrm{D}(2), \mathrm{E}(1), \mathrm{F}(1), \mathrm{G}(3), \mathrm{H}(16)$, and I(36).

\section{Results}

Figure 2 shows the calibration curve of a mechanical aneroid sphygmomanometer. It was noted that the calibrated sphygmomanometer exhibited a negative indication error, and as a result this equipment tends to provide a lower than true pressure reading. The indication error exceeded the reference value $( \pm 3 \mathrm{mmHg}$ ) at points along the nominal range equal to $70,90,100,120,150,190$ and $230 \mathrm{mmHg}$. In turn, the hysteresis error exceeded $4 \mathrm{mmHg}$ at the upper end of the nominal range. Similar error curves were realized for all calibrated sphygmomanometers.

The authors highlight in the following the results for the number of devices that were evaluated and from among such presented noncompliance, along with the percentage representation for this number from the total of the 72 evaluated devices:

- In 16 devices (22.2\%), the pointer was not within of the tolerance zone of scale mark at zero and 42 devices $(58.3 \%)$ showed an indication error higher than the maximum permitted error $( \pm 3.0 \mathrm{mmHg})$; 
- 7 devices (9.7\%) exceeded the maximum error stipulated for the hysteresis $(4 \mathrm{mmHg})$, this means that the quality of the elastic sensing element of these devices is not appropriate and must be replaced;

- 24 devices (33.3\%), demonstrated noncompliance conditions in the bladder and connection hoses, sleeve, hand pump and deflation valve;
- 11 devices (15.3\%) presented crack and damage on the display likely caused by falls and / or shocks. For this reason, they are indicated as unfit for use.

Table 1 shows the number of devices unsuitable for use in each department. From a total of 72 evaluated aneroid sphygmomanometers, $44(61.1 \%)$ did not meet the specifications in at least one of the tests, which may lead

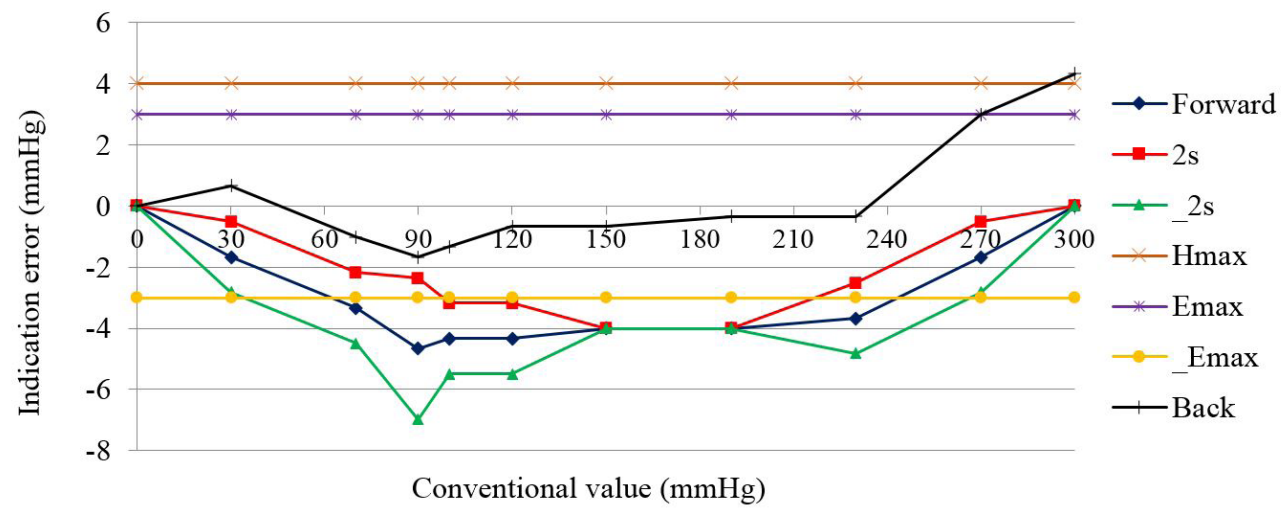

Figure 2. Error curves for a mechanical aneroid sphygmomanometer. Forward- Indication error; 2s- Indication error plus two standard deviations; _2s- Indication error minus two standard deviations; Hmax- Maximum error for hysteresis; Emax- Maximum positive error; _Emax- Maximum negative error; Back- Hysteresis error; s- standard deviation of the error.

Table 1. Number of devices unsuitable for use by department from the hospital.

\begin{tabular}{|c|c|c|c|}
\hline Department & $\begin{array}{l}\text { Number of devices with } \\
\text { non-conformities }\end{array}$ & $\begin{array}{l}\text { Devices unsuitable for } \\
\text { use in the department } \\
(\%)\end{array}$ & $\begin{array}{l}\text { Devices unsuitable for use for the sample taken } \\
\text { from the department in relation to the sample } \\
\text { taken from the hospital (\%) }\end{array}$ \\
\hline Pediatric clinic & 5 & 45.5 & 11.4 \\
\hline Pediatric ICU & 0 & 0 & 0 \\
\hline Oncology & 2 & 50.0 & 4.5 \\
\hline Pediatric aid post & 0 & 0 & 0 \\
\hline Pediatrics & 3 & 75.0 & 6.8 \\
\hline Gynecologic clinic & 2 & 66.7 & 4.5 \\
\hline Surgical emergency & 3 & 100.0 & 6.8 \\
\hline Surgical center II & 4 & 57.2 & 9.2 \\
\hline Obstetric center & 1 & 100.0 & 2.3 \\
\hline Hemodialysis & 1 & 50.0 & 2.3 \\
\hline Psychiatric & 1 & 50.0 & 2.3 \\
\hline Medical clinic & 4 & 66.7 & 9.2 \\
\hline First aid post & 0 & 0 & 0 \\
\hline Surgical center $\mathrm{V}$ & 2 & 66.7 & 4.5 \\
\hline Adult ICU & 3 & 75.0 & 6.8 \\
\hline Surgical center I & 2 & 33.3 & 4.5 \\
\hline Maternity & 1 & 50.0 & 2.3 \\
\hline Gynecologic aid post & 2 & 66.7 & 4.5 \\
\hline $\begin{array}{l}\text { Thoracic pain } \\
\text { emergency }\end{array}$ & 2 & 66.7 & 4.5 \\
\hline Surgical center III & 2 & 100.0 & 4.5 \\
\hline Emergency room & 2 & 66.7 & 4.5 \\
\hline Infectious disease & 1 & 100.0 & 2.3 \\
\hline Burned & 1 & 100.0 & 2.3 \\
\hline
\end{tabular}


to misdiagnose. These non-conformities were associated with the calibration and conditions of the manometer or integrity of the cuff, hand pump and deflation valve. These problems affect the accuracy of ABP readings.

\section{Uncertainty associated with the calibration of mechanical aneroid sphygmomanometers}

Table 2 summarizes the evaluation of the uncertainty of measurement associated with the mechanical aneroid sphygmomanometer calibration at the $90 \mathrm{mmHg}$ point of the nominal range, which exhibited the highest standard deviation value. Also, in Table 2, the following variables are presented, IV - input variable, E - estimate, PD probability distribution $(\mathrm{t}-\mathrm{t}$ distribution, $\mathrm{N}-$ Normal distribution, $\mathrm{R}$ - Rectangular distribution), $\mathrm{DF}$ - degree of freedom, $\mathrm{SC}$ - sensitivity coefficient, $\Delta R_{E}$ - Correction due to the resolution of the sphygmomanometer, $\Delta C_{E}$ - Correction associated with the uncertainty of the sphygmomanometer calibration, $\Delta H_{E}$ - Hysteresis of the sphygmomanometer, $u$ - standard uncertainty, $u_{c}$ - Combined standard uncertainty, $v_{e f}$ - Effective degrees of freedom, $k$ - Coverage factor, $U$ - Expanded uncertainty, $S_{E 90}, S_{A S}$ and $S_{A D}$ represent the standard deviation of pressure on $90 \mathrm{mmHg}$, standard deviation on systolic pressure and standard deviation on diastolic pressure respectively. These variables were obtained and calculated according to the GUM (Joint..., 2008). From this table, it was concluded that the expanded uncertainty associated with the sphygmomanometer calibration is $3 \mathrm{mmHg}$ for a coverage factor of 2.00 and $95.45 \%$ of coverage probability. The variable that most contributed to the final calibration uncertainty was the hysteresis of the standard manometer, with $53 \%$ of contribution, followed by the sphygmomanometer resolution with $27 \%$. Figure 3 shows how the expanded uncertainty associated with sphygmomanometer calibration affects the values recommended by the National Heart Foundation of Australia (2016) for the classification of patients according to the systolic and diastolic blood pressure, respectively.

In Figure 3, the shaded range is the area of uncertainty as the expanded uncertainty values (U) are distributed on both sides of the limits of each interval, reducing significantly the range of values belonging to each class.

Table 2. Data for the uncertainty evaluation associated with the calibration of the mechanical aneroid sphygmomanometer at the mark of $90 \mathrm{mmHg}$, systolic pressure measurement $\left(\mathrm{P}_{\mathrm{AS}}\right)$ and diastolic pressure measurement $\left(\mathrm{P}_{\mathrm{AD}}\right)$.

\begin{tabular}{cccccccc}
\hline $\mathbf{I V}$ & $\mathbf{E}(\mathbf{m m H g})$ & $\mathbf{P D}$ & $\mathbf{D F}$ & $\mathbf{S C}$ & $\boldsymbol{u}(\mathbf{m m H g})$ & & \\
\hline$S_{E 90}$ & 0.7959 & $\mathrm{~N}$ & 34 & 1 & 0.1345 & $u_{c}(\mathrm{mmHg})$ & 1.3282 \\
$\Delta R_{E}$ & 1 & $\mathrm{R}$ & $\infty$ & 1 & 0.5774 & $v_{\text {ef }}$ & $\infty$ \\
$\Delta C_{M 90}$ & 1.39 & $\mathrm{~N}$ & $\infty$ & 1 & 0.6950 & $k$ & 2.00 \\
$\Delta H_{M 90}$ & 1.67 & $\mathrm{R}$ & $\infty$ & 1 & 0.9642 & $U(\mathrm{mmHg})$ & 2.6564 \\
$S_{A S}$ & 1.7320 & $\mathrm{t}$ & 2 & 1 & 1.0000 & $u_{c}(\mathrm{mmHg})$ & 1.4792 \\
$\Delta R$ & 1 & $\mathrm{R}$ & $\infty$ & 1 & 0.5774 & $v_{\text {ef }}$ & 9.58 \\
$\Delta C_{E}$ & 1.640 & $\mathrm{~N}$ & 32 & 1 & 0.8039 & $k$ & 2.26 \\
$\Delta H_{E}$ & 0.791 & $\mathrm{R}$ & $\infty$ & 1 & 0.4567 & $U(\mathrm{mmHg})$ & 3.3431 \\
$S_{A D}$ & 2.8868 & $\mathrm{t}$ & 2 & 1 & 1.6667 & $u_{c}(\mathrm{mmHg})$ & 1.8476 \\
$\Delta R$ & 1 & $\mathrm{R}$ & $\infty$ & 1 & 0.5774 & $v_{\text {ef }}$ & 3.02 \\
$\Delta C_{E}$ & 1.066 & $\mathrm{~N}$ & 32 & 1 & 0.5225 & $k$ & 3.18 \\
$\Delta H_{E}$ & 0.297 & $\mathrm{R}$ & $\infty$ & 1 & 0.1715 & $U(\mathrm{mmHg})$ & 5.8754 \\
\hline
\end{tabular}
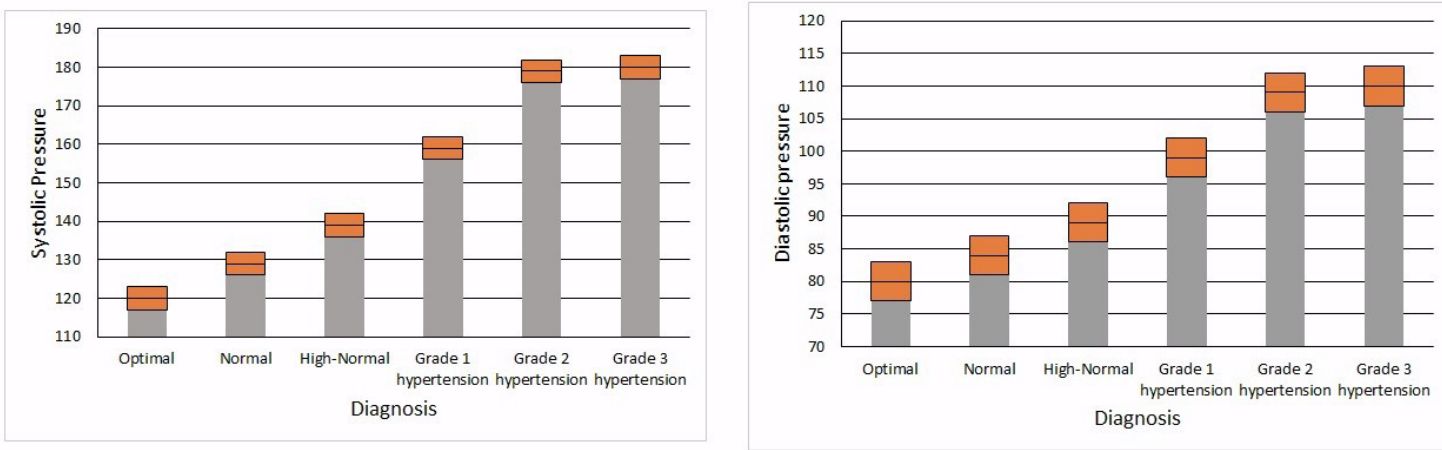

Figure 3. Graphic representation of the effect of expanded uncertainty associated with sphygmomanometers calibration (95\%) on the reference values for systolic pressure and diastolic pressure. 


\section{Blood pressure and the measurement uncertainty}

The average systolic (SBP) and diastolic (DBP) blood pressure were calculated from the 3 measurements for blood pressure by using an aneroid sphygmomanometer, which were calculated as $118 \mathrm{mmHg}$ and $77 \mathrm{mmHg}$, respectively; and the standard deviation associated with a $68 \%$ reliability factor was $1.7 \mathrm{mmHg}$ for SBP, and $2.9 \mathrm{mmHg}$ for DBP. Therefore, the repeatability of pressure values was low, and this could be justified through factors that acted upon the condition of the patient.

It was not detected any extreme point while applying the Chauvenet's criterion. The Shapiro-Wilk test has shown that pressure values indicated by sphygmomanometers during calibration, in the outward direction followed a normal distribution for a confidence level of $99 \%$. Hence, the methodology proposed on JCGM 100 (Joint..., 2008) can be applied to assess the uncertainty of measurement.

The evaluation of the uncertainty of measurement associated with the results for pressure measurements is summarized in Table 2. It can be concluded that the $\mathrm{SBP}$ is equal to $(118 \pm 4) \mathrm{mmHg}$ and the $\mathrm{DBP}$ is equal to $(77 \pm 6) \mathrm{mmHg}$ with a coverage factor of 2.26 and 3.18 , respectively. In both cases, the coverage probability is equal to $95 \%$ and the variable that most contributed to the final uncertainty was the variability of the values indicated by the sphygmomanometers, accounting for $46 \%$ for SBP and $81 \%$ for DBP.

\section{Discussion}

This study has shown that the scenario of non-conformity and lack of maintenance still occurred even though Ordinance No. 153 (Brasil, 2005) established the Metrological Technical Regulation for mechanical sphygmomanometers. The approval of this ordinance does not guarantee the reliability of measurement results, even with the compulsory Annual Verification of sphygmomanometers in the Health Care Facility.

In this study, $30.0 \%$ of all mechanical aneroid sphygmomanometers evaluated had the following non-conformity: the lack of integrity of the bladder and hand pump (e.g. presence of holes and worn out material); the sleeve with tears and patches; the deflation valve presented clogging and irregular functionality. This situation characterizes the lack of maintenance that could contribute toward inadequate measurement results. In this sense, it is essential that the operators take care when it comes to the condition of the bladder, hand pump and deflation valves, in addition to the Annual Verification of the devices.

This research has shown that $61.1 \%$ or 44 of the evaluated sphygmomanometers did not meet the specifications, and many of those were unsuitable for hospital use. These 44 aneroid sphygmomanometers should not be in use, instead, they should be sent for maintenance and receive appropriate repairs and/or adjustments. This fact can lead to an erroneous value of ABP. Therefore, decisions related to the diagnosis of hypertension and its therapeutic approach might be inadequate.

It is important to highlight that in the Pediatrics Clinic department, $45.0 \%$ of all evaluated devices were unsuitable for use.

Regarding the Periodic Verification, using the equipment management software, it was found that 26 of the 72 evaluated devices had exceeded their yearly Periodic Verification deadline, which is important for checking that the device maintains at least the minimum metrological characteristics throughout its working life. It is noteworthy that 15 of those 26 devices were unsuitable for use.

An alarming result was obtained in relation to the manometer of the trademark "E" that was being used in the hospital. This device did not have the mark of approval from INMETRO, which means that it has not passed any technical appraisal and as such, its commercialization is prohibited. Furthermore, this device showed the highest values of the Indication error $(20 \mathrm{mmHg})$ that may result in an inadequate misdiagnosis. This device was not registered in the equipment management software and was not among the trademarks acquired by the hospital. Hence, the device was not an integrated part of hospital property. The use of private equipment may represent risks to patient safety, as the responsibility for their maintenance and necessary verifications fall upon the owner, who may be unaware of such requirements.

The level of non-conformity found reflects a similar situation that was observed in 1997, when INMETRO conducted a verification on the calibration of the sphygmomanometers in use in four hospitals of the following cities: Rio de Janeiro, São Paulo and Juiz de Fora. In this study, public and private hospitals were chosen that attended to a large part of the population; and it was found that $61.0 \%$ of all evaluated sphygmomanometers were unsuitable for use (Monteiro and Lessa, 2005).

Other studies were performed, where similar results were obtained. The researchers in (Lessa et al., 2014) found that $64.4 \%$ of sphygmomanometers were inappropriate for use, all standard issue within the hospital network in Petropolis.

Again, (Mion et al., 2002) concluded that $72.0 \%$ of the evaluated devices had some kind of problem with the calibration of the manometer or integrity of the bladder, connection hoses, hand pump and valve for deflation.

The study by (Rouse and Marshall, 2001) found that $9.2 \%$, of the 1462 sphygmomanometers, gave reading errors of more than $5 \mathrm{~mm} \mathrm{Hg}$ and $19 \%$ gave reading 
errors of more than $2 \mathrm{mmHg}$. Further, (Moore et al., 2008) analyzed 282 aneroid sphygmomanometers for accuracy within $\pm 3 \mathrm{mmHg}$, their results showed that $33 \%$ of the aneroid sphygmomanometers failed with an error $>1 \mathrm{mmHg}$. The study presented by (Bailey et al., 1991) reported that $34.8 \%$ of the 230 aneroid sphygmomanometers failed with a reading error over $5 \mathrm{mmHg}$. The work of (Ali and Rouse, 2002) suggests that $10 \%$ of the 39 aneroid sphygmomanometers recorded an error greater than $10 \mathrm{mmHg}$.

Evinced from the obtained results is the need to estipulate a schedule for the verification of devices from any large hospital, as there does not exist a deadline for the sending of the device for maintenance. The results of studies by (Hussain and Cox, 1996) concluded that $23.5 \%$ of general practitioners never had their sphygmomanometers calibrated.

The number of devices unsuitable for use had fallen significantly from $60.5 \%$ in 2005 to $6.9 \%$ in 2008 , but reached $61.1 \%$ in the verification carried out in this study, which shows the decline in effectiveness of the metrological control being used. In this research, it was possible to identify which factors most contributed to the high level of the nonconformity. These were evaluated as the lack of knowledge on the part of the professionals as to when to send the devices for maintenance, carelessness in the usage (shocks) and in the storage of the devices, lack of replacement parts in stock, a single responsible technician overloaded with work, performing Eventual Verifications only upon request of the user, and the nonexistence of a schedule for carrying out Periodic Verifications.

In order to reverse this situation at the public hospitals, the following simple steps are suggested: being capacitation, storage and maintenance process of sphygmomanometers, an adequate number of professionals for performing maintenance, provide repair parts, and set a schedule for a Periodic Verification of all devices.

Capacitation could be done by professionals in order to be aware of the seriousness of the inherent problems from use of devices unsuitable for use or no calibrated. And the schedule should comply with the minimum requirement of one verification by year, and make it a continuous political of maintenance. The Periodic Verification should be performed based on the premises of the Agency of the Brazilian Network of the Legal Metrology and Quality - RBMLQ (IPEM) or at a place designated by INMETRO. The hospital where the study was performed has a Bioengineering department designed for the sphygmomanometers' calibration, accredited by the INMETRO, through the IPEM/MG.

The Metrological Control of aneroid sphygmomanometers is fundamental for ensuring the reliability of the results of pressure readings. This can be enhanced by observing the impact of the expanded uncertainty in blood pressure classification intervals. It is pertinent to emphasize that this narrowing of the blood pressure rating range can lead to incorrect diagnosis of normotensive in hypertensive individuals, thus depriving such individuals the benefits of treatment. On the other hand, the diagnosis of high blood pressure in normotensive individuals, will subject these to the risks and adverse effects of antihypertensive inappropriate treatment. The work of (Turner et al., 2006) quantified this inference by showing that mechanical aneroid sphygmomanometer, which were unfit for use, cause $20 \%$ of all undetected adult systolic, $28 \%$ of diastolic hypertension, and between $15 \%$ and $31 \%$ of all falsely detected adult systolic and diastolic hypertension. Further still, according to (Turner et al., 2004) if the measurement error of the sphygmomanometer is overestimated by $3 \mathrm{mmHg}$, for every five patients correctly diagnosed with hypertension, another four will be incorrectly diagnosed as hypertensive. If blood pressure is consistently underestimated at $3 \mathrm{mmHg}$, almost half of the patients (48\%) hypertensive would be diagnosed with normal pressure.

From the results obtained in this paper, one arrives at the conclusion that the measurement of blood pressure by the auscultatory method is an easy and routinized process in the Health Care Facilities. Nevertheless, to obtain the reliability of results, it is essential that requirements established by the current regulations are followed rigorously. The metrological reliability of equipment guarantees the patient the quality and safety habitually associated with health care and treatment, and thus preventing the occurrence of adverse events, misclassification, misdiagnosis, and inappropriate medical decisions.

\section{Acknowledgements}

The authors would like to thank Petrobras and the Brazilian financing agencies CAPES, CNPq and FAPEMIG for supporting the development of this research, and Bioengineering Department of Hospital of the Clinics of Uberlândia (HCU-UFU) for providing the sphygmomanometer aneroid.

\section{References}

Ali S, Rouse A. Practice audits: reliability of sphygmomanometers and blood pressure recording bias. Journal of Human Hypertension. 2002; 16(5):359-61. PMid:12082498. http:// dx.doi.org/10.1038/sj.jhh.1001384.

Bailey RH, Knaus VL, Bauer JH. Aneroid sphygmomanometers: an assessment of accuracy at a university hospital and clinics. Archives 
of Internal Medicine. 1991; 151(7):1409-12. PMid:2064493. http://dx.doi.org/10.1001/archinte.1991.00400070157022.

Brasil. Ministério do Desenvolvimento, Indústria e Comércio Exterior. Instituto Nacional de Metrologia, Qualidade e Tecnologia. Portaria Inmetro $\mathrm{n}^{\mathrm{o}}$ 153, de 12 de agosto de 2005. Diário Oficial da República Federativa do Brasil, Brasília, 2005 [cited 2015 Apr 29]. Available from: http://www.inmetro.gov. br/rtac/pdf/RTAC000966.pdf.

Hussain A, Cox JG. An audit of the use of sphygmomanometers. The British Journal of Clinical Practice. 1996; 50(3):136-7. PMid:8733331.

Instituto Nacional de Metrologia, Qualidade e Tecnologia. NIE-DIMEL-006: procedimentos de verificação e inspeção de esfigmomanômetros mecânicos [internet]. 2014 [cited 2015 Apr 29]. Available from: http://www.inmetro.gov.br/metlegal/ docDisponiveis.asp.

International Organization for Standardization. ISO/IEC 17025:2005. General requirements for the competence of testing and calibration laboratories. Geneva: ISO; 2005. 28 p.

International Organization of Legal Metrology. R16-1:2002: noninvasive mechanical sphygmomanometers. Paris: OIML; 2002.

Introcaso L. História da pressão arterial: 100 anos do esfigmomanômetro. Arquivos Brasileiros de Cardiologia. 1996; 67(5):305-11. PMid:9239863.

James PA, Oparil S, Carter BL, Cushman WC, DennisonHimmelfarb C, Handler J, Lackland DT, LeFevre ML, MacKenzie TD, Ogedegbe O, Smith SC Jr, Svetkey LP, Taler SJ, Townsend RR, Wright JT Jr, Narva AS, Ortiz E. Evidencebased guideline for the management of high blood pressure in adults: report from the panel members appointed to the Eighth Joint National Committee (JNC 8). Journal of the American Medical Association. 2014; 311(5):507-20. PMid:24352797. http://dx.doi.org/10.1001/jama.2013.284427.

Joint Committee for Guides in Metrology. JCGM 100: guide to the expression of uncertainty in measurement. Geneva: JCGM; 2008. 131 p.

Lessa V, Bernardo S, Garrido FSRG, Garrido RG. Manutenção e calibração de esfigmomanômetros: possíveis impactos na medição da pressão arterial. Colloquium Vitae. 2014; 6(3):91-8. http://dx.doi.org/10.5747/cv.2014.v06.n3.v116.

Mendonça GS, Souza DB, Milagre ST. Controle de qualidade dos esfigmomanômetros aneróides de um hospital universitário de grande porte. In: Proceedings of the $23^{\circ}$ Congresso Brasileiro de Engenharia Biomédica; 2012 Oct 1-5; Porto de Galinhas, Brazil. Rio de Janeiro: Editora da SBEB; 2012. p. 570-4.

Mendonça GS. Levantamento do perfil dos esfigmomanômetros aneróides do Hospital de Clínicas da Universidade Federal de Uberlândia por meio de avaliação eventual [monograph]. Uberlândia: Universidade Federal de Uberlândia; 2012. 82 p.

Minor DS, Butler KR Jr, Artman KL, Adair C, Wang W, McNair V, Wofford MR, Griswold M. Evaluation of blood pressure measurement and agreement in an Academic Health Sciences Center. Journal of Clinical Hypertension. 2012; 14(4):222-7. PMid:22458743. http://dx.doi.org/10.1111/j.17517176.2012.00599.x.
Mion D Jr, Pierin A, Lessa I, Nobre F. Aparelhos, técnicas de medida da pressão arterial e critérios de hipertensão adotados por médicos brasileiros. Estudo exploratório. Arquivos Brasileiros de Cardiologia. 2002; 79(6):593-6. PMid:12532243.

Monteiro EC, Lessa ML. A metrologia na área de saúde: garantia da segurança e da qualidade dos equipamentos eletromédicos. Engevista. 2005; 7(2):51-60.

Moore TA, Sorokin AV, Hirst C, Thornton-Thompson S, Thompson PD. The accuracy of aneroid sphygmomanometers in the ambulatory setting. Journal of Preventive Cardiology. 2008; 11(2):90-4. PMid:18401236. http://dx.doi.org/10.1111/j.17517141.2008.06600.x.

Moreira LF. The Archives and the publication of its first impact factor. Arquivos Brasileiros de Cardiologia. 2010; 95(1):1-51. PMid:20694399.

National Heart Foundation of Australia. Guideline for the diagnosis and management of hypertension in adults -2016 . Melbourne: National Heart Foundation of Australia; 2016.

Pater C. Beyond the evidence of the new hypertension guidelines. Blood pressure measurement: is it good enough for accurate diagnosis of hypertension? Time might be in, for a paradigm shift (I). Current Controlled Trials in Cardiovascular Medicine. 2005; 6(1):6. PMid:15813975. http://dx.doi.org/10.1186/14686708-6-6.

Pickering TG, Hall JE, Appel LJ, Falkner BE, Graves JW, Hill MN, Jones DH, Kurtz T, Sheps SG, Roccella EJ. Recommendations for blood pressure measurement in humans: an AHA scientific statement from the Council on High Blood Pressure Research Professional and Public Education Subcommittee. Journal of Clinical Hypertension. 2005; 7(2):102-9. PMid:15722655. http://dx.doi.org/10.1111/j.1524-6175.2005.04377.x.

Pickering TG, Ogedegbe G. Principles and techniques of blood pressure measurement. Cardiology Clinics. 2010; 28(4):571-86. PMid:20937442. http://dx.doi.org/10.1016/j.ccl.2010.07.006.

Piper MA, Evans CV, Burda BU, Margolis KL, O’Connor E, Whitlock EP. Diagnostic and predictive accuracy of blood pressure screening methods with consideration of rescreening intervals: a systematic review for the U.S. Preventive Services Task Force. Annals of Internal Medicine. 2015; 162(3):192204. PMid:25531400. http://dx.doi.org/10.7326/M14-1539.

Powers BJ, Olsen MK, Smith VA, Woolson RF, Bosworth $\mathrm{HB}$, Oddone EZ. Measuring blood pressure for decision making and quality reporting: where and how many measures? Annals of Internal Medicine. 2011; 154(12):781-8, W-289-90. PMid:21690592. http://dx.doi.org/10.7326/0003-4819-15412-201106210-00005.

Rouse A, Marshall T. The extent and implications of sphygmomanometer calibration error in primary care. Journal of Human Hypertension. 2001; 15(9):587-91. PMid:11550103. http://dx.doi.org/10.1038/sj.jhh.1001241.

Tolonen H, Koponen P, Naska A, Männistö S, Broda G, Palosaari $\mathrm{T}$, Kuulasmaa K. Challenges in standardization of blood pressure measurement at the population level. BMC Medical Research Methodology. 2015; 15(1):33. PMid:25880766. http://dx.doi. org/10.1186/s12874-015-0020-3.

Turner MJ, Irwig L, Bune AJ, Kam PC, Baker AB. Lack of sphygmomanometer calibration causes over- and under-detection 
of hypertension: a computer simulation study. Journal of Hypertension. 2006; 24(10):1931-8. PMid:16957551. http:// dx.doi.org/10.1097/01.hjh.0000244940.11675.82 .

Turner MJ, Kam PC, Baker AB. Metrology in Medicine. Proceedings of the 5th Biennial Conference of the Metrology Society of Australia [internet]. 2004 March [cited 2016 Aug 17]; 1(1):[about 6 p]. Available from: https://www.researchgate. net/profile/Stephan_Mieke/publication/229650616_Metrology_ in_Medicine/links/558bdf5708aee43bf6ad04ad.pdf.

Weckenmann A, Knauer M, Killmaier T. Uncertainty of coordinate measurements on sheet-metal parts in the automotive industry. Journal of Materials Processing Technology. 2001; 115(1):9-13. http://dx.doi.org/10.1016/S0924-0136(01)00758-0.

World Health Organization. Guidelines for the management of hypertension. Journal of Hypertension. 1999; 17(2):151-83. PMid:10067786.

Yang Q, Cogswell ME, Flanders WD, Hong Y, Zhang Z, Loustalot F, Gillespie C, Merritt R, Hu FB. Trends in cardiovascular health metrics and associations with all-cause and CVD mortality among US adults. Journal of the American Medical Association. 2012; 307(12):1273-83. PMid:22427615. http:// dx.doi.org/10.1001/jama.2012.339. 